Article

\title{
Antipyretic, Antinociceptive, and Anti-Inflammatory Activities from Pogostemon benghalensis Leaf Extract in Experimental Wister Rats
}

\author{
Sushant Aryal ${ }^{1,2}$ (), Balkrishna Adhikari ${ }^{1}$, Kasmira Panthi ${ }^{1}$, Pramod Aryal ${ }^{1,3}$, \\ Shyam Kumar Mallik ${ }^{4}$, Ram Prasad Bhusal ${ }^{1,3, *}{ }^{\mathbb{C}}$, Bahare Salehi ${ }^{5}{ }^{\circ}$, William N. Setzer ${ }^{6,7}$, \\ Javad Sharifi-Rad ${ }^{8, *(\mathbb{D})}$ and Niranjan Koirala $2,9, *$ (D) \\ 1 Department of Pharmacy, Universal College of Medical Sciences, Tribhuvan University, Bhairahawa, \\ Rupandehi 32900, Nepal; sushantar123@gmail.com (S.A.); himalac22@gmail.com (B.A.); \\ panthikashmira@gmail.com (K.P.); a.prayal2@gmail.com (P.A.) \\ 2 Department of Natural Products Research, Dr. Koirala Research Institute for Biotechnology and Biodiversity, \\ Kathmandu 44600, Nepal \\ 3 Department of Biochemistry and Molecular Biology, Monash University, Clayton, VIC 3800, Australia \\ 4 Department of Pharmacy, Purbanchal University College of Medical and Allied Sciences, Biratnagar, \\ Morang 56613, Nepal; symlik@gmail.com \\ 5 Student Research Committee, School of Medicine, Bam University of Medical Sciences, Bam 44340847, Iran; \\ bahar.salehi007@gmail.com \\ 6 Department of Chemistry, University of Alabama in Huntsville, Huntsville, AL 35899, USA; \\ setzerw@uah.edu \\ 7 Aromatic Plant Research Center, 230 N 1200 E, Suite 100, Lehi, UT 84043, USA \\ 8 Zabol Medicinal Plants Research Center, Zabol University of Medical Sciences, Zabol 61615-585, Iran \\ 9 Department of Civil and Environmental Engineering, Faculty of Science and Technology, University of \\ Macau, Macau SAR 999078, China \\ * Correspondence: ram.bhusal@monash.edu (R.P.B.); javad.sharifirad@gmail.com (J.S.-R.); \\ koirala.biochem@gmail.com (N.K.)
}

Received: 22 August 2019; Accepted: 9 September 2019; Published: 20 September 2019

\begin{abstract}
Background: Pogostemon benghalensis leaves have traditionally been utilized for relieving body aches, headaches and fever. Based on its uses, the present study was designed to investigate the antinociceptive, antipyretic and anti-edematogenic activities from $P$. benghalensis leaves' methanol extract (PBME) in Wister rats. Methods: The thermal (hot plate) and chemical (acetic acid-induced writhing and formalin test) models for antinociceptive effects, and the Brewer's yeast induced hyperthermia test for antipyretic action and rat paw edema by carrageenan for anti-edematogenic activity, were applied for PBME at different dose levels. The acute toxicity of PBME through the oral route was performed to determine the lethal dose. Results: PBME significantly and dose-dependently reduced pyrexia and diminished edema volume, which depicted its antipyretic and anti-edematogenic effects respectively. The inhibition of writhing reflex, increased reaction latency and reduced frequency of licking indicated that PBME has significant dose-dependent antinociceptive activity. P. benghalensis methanol extract at $4000 \mathrm{mg} / \mathrm{kg}$ shows no sign of toxicity, which is a considerable, good margin of safety. Conclusions: The study illustrated the antipyretic, antinociceptive and anti-inflammatory potential of $P$. benghalensis leaf extract with a safety margin, and validated its traditional use to alleviate fever, pain, and inflammation.
\end{abstract}

Keywords: Pogostemon benghalensis; antipyretic; antinociceptive; anti-inflammatory; PBME; methanolic extract 


\section{Introduction}

Pain, pyrexia, and inflammation are the primary indicators of many clinical conditions associated with injury, trauma, or infections [1]. Pain is defined by the International Association for the Study of Pain as, 'an unpleasant sensory and emotional experience associated with actual or potential tissue damage, or described in terms of such damage' [2]. Whereas, pyrexia is the characteristic defensive host mechanism of an increase in body temperature, occurring in response to pyrogenic infection, malignancy, or other diseases [3]. Inflammation is characterized by erythema, edema, heat, and pain initiated by the biological defensive mechanism to remove injurious stimuli [4]. Many therapeutic agents, such as NSAIDs, opioids, and steroids are available for the treatment of such disorders, but their potential side effects including bleeding, peptic ulcers, mental dependence, tolerance, and addiction, so have limited their clinical use [5]. Therefore, new plant-based drugs with low adverse effects are of current global research interest because plants are considered to be novel reservoirs [6].

Literature reports have widely recognized plant based herbal medicines for their better therapeutic value and less adverse effects compared to modern medicines [7,8]. Globally, around 80 per cent of the population in third world countries, including Nepal, relies on herbal remedies as a major form of health practice [9]. In addition, many developed nations from Europe, North America, and Australia have widely embraced the herbal-based complementary and alternative medicines (CAMs) as a part of their health care systems [10]. Nevertheless, the knowledge of traditional medicinal plants stills remains with indigenous people despite is global scope [11]. Investigation into the use of ethno-medicinal plants by scientists could be a valuable asset to discovering new medicinal products [12].

Pogostemon bengalensis from the Lamiaceae family is a small perennial shrub, 1-2 $\mathrm{m}$ tall, commonly known as Rudhilo in Nepal [13,14]. Traditionally, the leaf extract was used for the alleviation of fever [15] and its paste was given orally for the treatment of body pain [16]. The traditional formulation of leaves juices with sterculia gum and sesame oil are used in treatment of piles [17]. Moreover, pounded $P$. bengalensis leaves were inhaled and placed onto the forehead of patients for the treatments of coughs, colds, and headaches [18], suggesting the leaves to be a highly used part of the plant in folklore medicine. Phytochemical studies on P. bengalensis have shown the existence of phenols, flavonoids, alkaloids, saponins, terpenoids, and steroidal constituents as the principal active ingredients [19]. Scientifically, various medicinal properties have been reported, including antimicrobial activity against E. coli, S. aureus, P. vulgaris, and A. parasiticus; antifungal activity against C. albicans [20]; and antiviral against $S$. virus [21]. The extracts of $P$. bengalensis were investigated on ehrlich ascites carcinoma (EAC) induced mice, which significantly reduced the solid tumor volume [19].

Considering the use of $P$. bengalensis leaves in traditional folk remedies for pain, fever, and edema, this study is aimed to ascertain its pharmacotherapeutic value using experimental animal models.

\section{Materials and Methods}

\subsection{Chemicals and Drugs}

Carrageenan (S D Fine-Chem Limited, Mumbai, India), aspirin (Aristo Pharmaceuticals Pvt Ltd, Mumbai, India), indomethacin (Glenmark Pharmaceuticals, Mumbai, India), morphine (Modi Mundi Pharma Pvt. Ltd, New Delhi, India), Brewer's yeast (Itanbiotech. Ltd, New Delhi, India), and naloxone (Samarth Life Sciences Pvt. Ltd., Mumbai, India) were purchased all from Indian companies. All reagents used in the research were of analytical grade.

\subsection{Plant Material}

The leaves of Pogostemon benghalensis (Burm.f.) Kuntze were collected on June 2016 from Gorkha, Nepal. The plant was authenticated from the National Botanical Garden, Department of Plant Resources, Ministry of Forest and Soil Conservation, Nepal. The voucher specimen (UHS1602) of collected plants was preserved in the Pharmacognosy Laboratory, Department of Pharmacy, Universal College of Medical Sciences, Tribhuvan University, Nepal. 


\subsection{Preparation of Plant Extract}

The leaves collected from $P$. bengalensis were used for the preparation of methanol extract (PBME). Firstly, the raw leaves were dehydrated under shade and pulverized by mortar and pestle. The pulverized powder was macerated with methanol in an Erlenmeyer flask at room $25^{\circ} \mathrm{C}$ for 15 days with intermittent agitation. The extract was filtered by a vacuum filter and concentrated in a rotavapor (Büchi Labortechnik, Essen, Germany) under reduced pressure and controlled temperature $\left(40-50{ }^{\circ} \mathrm{C}\right.$ ) to give an extract with a $3.8 \%$ percentage yield, which was kept at $4{ }^{\circ} \mathrm{C}$ until further use.

\subsection{Animals and Ethical Approval}

Wistar rats of both sexes, weighing 150-250 g were obtained from the Animal House, Department of Pharmacy, Universal College of Medical Sciences, Tribhuvan University, Nepal. These animals had free access to standard feed and water ad libitum. They were kept in clean polypropylene cages with wooden dust (replaced every three days) under controlled temperature $\left(22 \pm 1^{\circ} \mathrm{C}\right)$, maintaining a 12/12 h light/dark cycle. The animal care, handling and experimental protocols were carried out in strict compliance with official ethical guidelines of Nepal $[8,22]$. Animals were submitted to 35\% $\mathrm{CO}_{2}$ euthanasia after completion of the study. All experimental procedures were approved by the Institutional Review Committee, Universal College of Medical Sciences, Tribhuvan University (Ref: UCMS/IRC/077/16). The approval date is 28 October 2016.

\subsection{Acute Toxicity Studies}

Organization of Economic Cooperation and Development (OECD) guidelines was adopted to carried out acute toxicity studies [23]. Animals were divided into five groups $(n=6)$ : four test groups and a control group. The test groups were treated with PBME (500, 1000, 2000, and $4000 \mathrm{mg} / \mathrm{kg}$, p.o.) at $10 \mathrm{~mL} / \mathrm{kg}$ and a control with vehicle (saline). The any sign of toxic effects and mortality were observed every $1 \mathrm{~h}$ for the next $6 \mathrm{~h}$ and body weight was measured on day 1,7 and 14 after treatments.

\subsection{Acetic Acid-Induced Writhing Test}

The test procedure followed the method as described by Pingsusaen et al., 2015 [24]. Six groups $(n=6)$ of rats were assigned for this experimental model; Group A: vehicle (control, saline, p.o.), Group B: indomethacin (10 mg/kg, p.o.), Groups C-E: PBME (100, 200, and $400 \mathrm{mg} / \mathrm{kg}$, p.o., respectively), Group F: PBME (400 mg/kg, p.o.) + naloxone ( $5 \mathrm{mg} / \mathrm{kg}$, p.o., treated $30 \mathrm{~min}$ prior of PBME administration). Thirty minutes post-dosing, $0.6 \%$ acetic acid $(10 \mathrm{~mL} / \mathrm{kg})$ was injected intraperitoneally. The number of cumulative writhes was documented for $30 \mathrm{~min}$. Inhibition percentage was calculated as in following equation: Inhibition $(\%)=\left(\left(\mathrm{A}_{\text {Control }}-\mathrm{B}_{\text {Test }}\right) / \mathrm{A}_{\text {Control }}\right) \times 100$, where, $\mathrm{A}$ is the mean writhes in control group and $\mathrm{B}$ is the mean writhes in test groups.

\subsection{Thermal Test}

The experiment followed the procedures reported by Sulaiman et al., 2008 [25]. Forty-two Wister rats were assigned to seven groups $(n=6)$. Group A: vehicle (control, saline, p.o.), Group B: morphine (5 mg/kg, p.o), Group C-E: PBME (100, 200, and 400 mg/kg, p.o.), Group F: PBME (400 mg/kg, p.o.) + naloxone (5 mg/kg, p.o.), and Group G: morphine (5 mg/kg, p.o) + naloxone (5 mg/kg, p.o.). Animals in Group F and $\mathrm{G}$ were treated with naloxone 30 min prior the administration of PBME or morphine. Thirty minutes post-dosing, each rat was placed in an Eddy's hot-plate apparatus with a metal surface temperature of $55 \pm 0.2^{\circ} \mathrm{C}$. Latency to discomfort (paw licking or jumping) was recorded by the time between placement in platform and the reaction provoked with 30 s cut-off time.

\subsection{Formalin Test}

The test procedure adopted the model as reported in the Sulaiman et al., 2008 literature [25]. Thirty-six rats were randomly assigned to six groups $(n=6)$. Group A: vehicle (control, saline, 
p.o.), Group B: morphine (5 mg/kg, p.o), Group C: aspirin (100 mg/kg, p.o.), Group D-F: PBME (100, 200 , and $400 \mathrm{mg} / \mathrm{kg}$, p.o.). Thirty minutes post-dosing, $2.5 \%(v / v)$ formalin ( $40 \%$ formaldehyde) in normal saline $(50 \mu \mathrm{L} / \mathrm{rat})$ was intraplantarly injected into the right paw, and the cumulative duration of licking was recorded at 5-10 min (neurogenic pain phase) and 20-30 min (inflammatory pain phase) post-formalin injection. The inhibition percentage was calculated as equation: Inhibition $(\%)=\left(\left(\mathrm{A}_{\text {Control }}-\mathrm{B}_{\text {Test }}\right) / \mathrm{A}_{\text {Control }}\right) \times 100$, where, $\mathrm{A}$ and $\mathrm{B}$ are the duration of paw licking in the control group and test groups respectively.

\subsection{Antipyretic Activity}

Hyperthermia induced by Brewer's yeast on Wister rats model was adopted to investigate the antipyretic action of $P$. bengalensis extract [24]. Initially, rectal temperatures of rats were recorded. Subcutaneously $20 \% \mathrm{w} / \mathrm{v}$ Brewer's yeast suspension $(10 \mathrm{~mL} / \mathrm{kg})$ was injected in each rats to induce hyperthermia. Eighteen hours post-injection, rectal temperature of each fasted-rats was recorded to ensure pyrexia. Accordingly, thirty rats were randomly assigned to five groups $(n=6)$. Group A: vehicle (control, saline, p.o.), Group B: paracetamol (100 mg/kg), and Group C-E: PBME (100, 200, and $400 \mathrm{mg} / \mathrm{kg}$, p.o.). The rectal temperature was documented after 1, 2, 3, and $4 \mathrm{~h}$ post-dosing and antipyretic activity was expressed in term of ${ }^{\circ} \mathrm{F}$.

\subsection{Anti-Inflammatory Activity}

To evaluate anti-inflammatory effect of $P$. bengalensis extract, a rat paw edema model induced by carrageenan was adopted [24]. Thirty selected Wister rats were randomly assigned to five groups $(n=6)$. Group A: vehicle (control, saline, p.o.), Group B: indomethacin $(10 \mathrm{mg} / \mathrm{kg}$ p.o.), and Group C-E: PBME (100, 200, and $400 \mathrm{mg} / \mathrm{kg}$, p.o.). Thirty minutes post-dosing, $50 \mu \mathrm{L}$ of $1 \%$ (w/v) carrageenan was injected subplantarly into right hind paw. Change in paw volume was recorded for $6 \mathrm{~h}$ postcarrageenan injection and anti-edematogenic effect is expressed using the formula: final paw volume $(1,2,3,4$ and $5 \mathrm{~h})$ - initial paw volume $(0 \mathrm{~h})$.

\subsection{Data Analysis}

The experimental outcomes are expressed as mean $\pm \mathrm{SD}$ and statistical analysis was performed by GraphPad Prism 7 software. Multiple comparisons were performed with one-way ANOVA, followed by Dunnett's test to determine the significance level in models, such as for nociceptive activity, Brewer's yeast induced hyperthermia, and carrageenan-induced rat paw edema. $p$-values $<0.05$ were considered significant.

\section{Results}

\subsection{Acute Toxicity Study}

At the maximum administered dose of PBME $(4000 \mathrm{mg} / \mathrm{kg})$, no mortality or toxicity symptoms was observed during the 14-day observation period. Therefore, oral administration of PBME had a good safety margin.

\subsection{Acetic Acid-Induced Writhing Reflex}

The PBME (100, 200, or $400 \mathrm{mg} / \mathrm{kg}$, p.o.) showed a significant $\left({ }^{*} p<0.05\right)$ and dose-dependent inhibition in the number of abdominal writhes (Table 1), with the percentage reduction ranging between $33 \%$ and $68 \%$. The observed effect of PBME $(400 \mathrm{mg} / \mathrm{kg}$ ) was highly comparable to the effect of indomethacin $(10 \mathrm{mg} / \mathrm{kg})$, with no significant reverse action on the PBME $(400 \mathrm{mg} / \mathrm{kg})+$ naloxone (5 mg/kg) treated group. 
Table 1. Result of Pogostemon benghalensis leaves' extracts on the acid-induced writhing reflex.

\begin{tabular}{llll}
\hline \multicolumn{1}{c}{ Treatment Groups } & Dose $(\mathbf{m g} / \mathbf{k g}, \mathbf{p . o .})$ & \multicolumn{1}{c}{ No. Writhings } & Inhibition \% \\
\hline Control & & $37.33 \pm 1.03$ & \\
& 100 & $25.00 \pm 1.41^{*}$ & 33.03 \\
PBME & 200 & $18.50 \pm 1.05 *$ & 50.44 \\
& 400 & $11.33 \pm 0.81 *$ & 69.65 \\
PBME $(400 \mathrm{mg})+$ naloxone $(5 \mathrm{mg} / \mathrm{kg})$ & & $13.11 \pm 0.89$ & 64.88 \\
Indomethacin $(10 \mathrm{mg} / \mathrm{kg})$ & 10 & $11.67 \pm 1.21^{*}$ & 68.74 \\
\hline
\end{tabular}

$n=6$; values are mean $\pm \mathrm{SD}$; $p$-value measured by ANOVA followed by Dunnett's post hoc multiple comparisons.

${ }^{*} p<0.05$ compared to the control group.

\subsection{Thermal Test}

The PBME $\left(100,200\right.$, or $400 \mathrm{mg} / \mathrm{kg}$, p.o.) also showed a significant $\left({ }^{*} p<0.05\right)$ increase in pain threshold via thermally induced nociception model (Table 2). The dose-dependent rise in latency time was observed in PBME-dosing groups. The observed antinociceptive activity of PBME $(400 \mathrm{mg} / \mathrm{kg})$ was similar to that of morphine $(5 \mathrm{mg} / \mathrm{kg})$ with no significant reverse action on the PBME $(400 \mathrm{mg} / \mathrm{kg})$ + naloxone $(5 \mathrm{mg} / \mathrm{kg})$ treated group.

Table 2. Time course effect of $P$. benghalensis leaves' extracts on the thermal model.

\begin{tabular}{|c|c|c|c|c|c|c|}
\hline \multirow{2}{*}{ Sample } & \multirow{2}{*}{$\begin{array}{c}\text { Dose } \\
(\mathrm{mg} / \mathrm{kg}, p . o)\end{array}$} & \multicolumn{5}{|c|}{ Latency Time (min) } \\
\hline & & 0 & 30 & 60 & 120 & 240 \\
\hline Control & & $14.8 \pm 0.7$ & $15.4 \pm 1.0$ & $15.2 \pm 0.8$ & $14.8 \pm 1.0$ & $15.2 \pm 0.7$ \\
\hline \multirow{2}{*}{ PBME } & 200 & $15.2 \pm 0.8$ & $16.0 \pm 1.41$ & $17.6 \pm 1.5 *$ & $20.4 \pm 1.2 * \#, \mathrm{a}$ & $19.2 \pm 1.5 * \#, \mathrm{a}$ \\
\hline & 400 & $15.0 \pm 0.5^{*}$ & $21.0 \pm 0.7 *$ & $24.0 \pm 0.7^{*, \#}$ & $26.0 \pm 1.0 *$ & $25.0 \pm 0.9 * \#$ \\
\hline $\begin{array}{l}\text { Morphine }(5 \mathrm{mg} / \mathrm{kg}) \\
+ \text { naloxone }(5 \mathrm{mg} / \mathrm{kg})\end{array}$ & & $15.0 \pm 0.2^{*, a}$ & $15.3 \pm 0.6^{*, \mathrm{a}}$ & $15.2 \pm 0.8^{*, \mathrm{a}}$ & $15.1 \pm 0.3 *, a$ & $15.1 \pm 0.7^{*, \mathrm{a}}$ \\
\hline
\end{tabular}

$n=6$. Values are mean \pm SD; $p$-value measured by ANOVA followed by Dunnett's post hoc multiple comparisons.

${ }^{*} p<0.05$ compared to control. ${ }^{\#} p<0.01$ compared to morphine $(5 \mathrm{mg} / \mathrm{kg})+$ naloxone $(5 \mathrm{mg} / \mathrm{kg}) ;{ }^{a} p<0.05$ compared

to PBME $(400 \mathrm{mg})+$ naloxone $(5 \mathrm{mg} / \mathrm{kg})$.

\subsection{Formalin Test}

Intra-plantar injection of $2.5 \%(v / v)$ formalin on the right paw increase the duration of licking (Table 3 ). However, the pre-dosing of rats with PBME (100, 200, or $400 \mathrm{mg} / \mathrm{kg}$, p.o.) reduced the licking duration. The calculated percentage inhibition ranged from $49 \%$ to $73 \%$ in the neurogenic pain phase and $56 \%$ to $85 \%$ in the inflammatory pain phase. The comparisons revealed that the effect of PBME $(400 \mathrm{mg} / \mathrm{kg}$ ) was similar to that of morphine $(5 \mathrm{mg} / \mathrm{kg})$ on initial phase and aspirin $(100 \mathrm{mg} / \mathrm{kg})$ on late phase.

Table 3. Result of P. benghalensis leaves' extracts on the formalin test.

\begin{tabular}{cccc}
\hline \multirow{2}{*}{ Sample } & \multirow{2}{*}{$\begin{array}{c}\text { Dose } \\
(\mathbf{m g} / \mathbf{k g} \text {, p.o. })\end{array}$} & \multicolumn{2}{c}{ Duration of Licking (s) (Inhibition \%) } \\
\cline { 3 - 4 } & & Initial Phase $\mathbf{( 0 5}-\mathbf{1 0 ~} \mathbf{m i n})$ & Late Phase (20-30 min) \\
\hline Control & 100 & $66.0 \pm 1.58$ & $63.6 \pm 3.28$ \\
& 200 & $34.0 \pm 1.58 *(48.48)$ & $27.8 \pm 0.83 *(56.29)$ \\
PBME & 400 & $26.2 \pm 0.83 *(60.303)$ & $20.4 \pm 1.51 *(67.925)$ \\
& 100 & $63.0 \pm 1.00(04.54)$ & $7.4 \pm \pm 1.14 *(85.22)$ \\
Aspirin & 5 & $15.8 \pm 0.84 *(76.06)$ & $9.8 \pm 1.30 *(88.36)$ \\
Morphine & 5 &
\end{tabular}

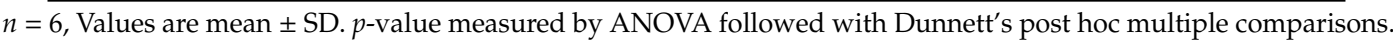
$* p<0.05$ compared to control. 


\subsection{Antipyretic Effect}

The PBME (100, 200, and $400 \mathrm{mg} / \mathrm{kg}$ p.o.) displayed a significant $\left.{ }^{*} p<0.05\right)$ decrease to elevated temperature in a dose-dependent manner (Figure 1). The antipyretic efficacy with the highest significant effect was observed at 2 and $3 \mathrm{~h}$. The $400 \mathrm{mg} / \mathrm{kg}$ PBME demonstrated an antipyretic activity that was comparable to the positive control group paracetamol $(100 \mathrm{mg} / \mathrm{kg})$.

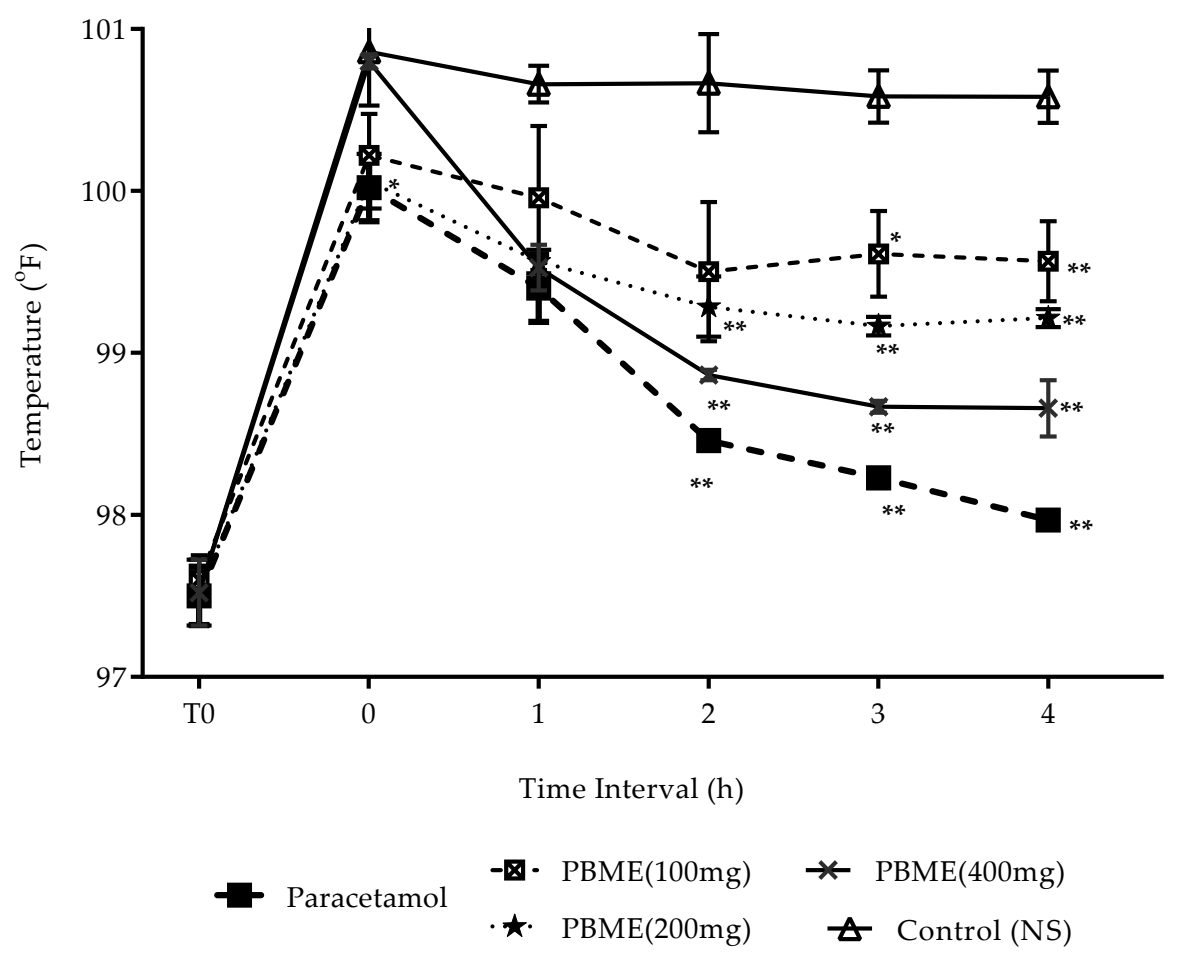

Figure 1. Antipyretic activity effect of $P$. benghalensis leaves' methanol extract (PBME) and paracetamol in Brewer's yeast induced hyperthermia rats. Values are mean $\pm \operatorname{SD}(n=6)$. $p$-value measured by ANOVA followed with Dunnett's post hoc multiple comparisons. ${ }^{*} p<0.01$, and ${ }^{* *} p<0.001$ compared to control.

\subsection{Anti-Inflammatory Activity}

Sub-plantar injection of $1 \%(w / v)$ carrageenan on the right hind paw increased the edema volume (Figure 2). However, the pre-dosing of rats with PBME (100, 200, or $400 \mathrm{mg} / \mathrm{kg}$, p.o.) produced a significant $\left.{ }^{*} p<0.05\right)$ decrease in edema volume in a dose-dependent manner. The data revealed the efficacy of PBME $(400 \mathrm{mg} / \mathrm{kg})$ is slightly lower, but on a par to indomethacin $(10 \mathrm{mg} / \mathrm{kg})$, with highest reduction in paw volume being at $3 \mathrm{~h}$ post administration. 


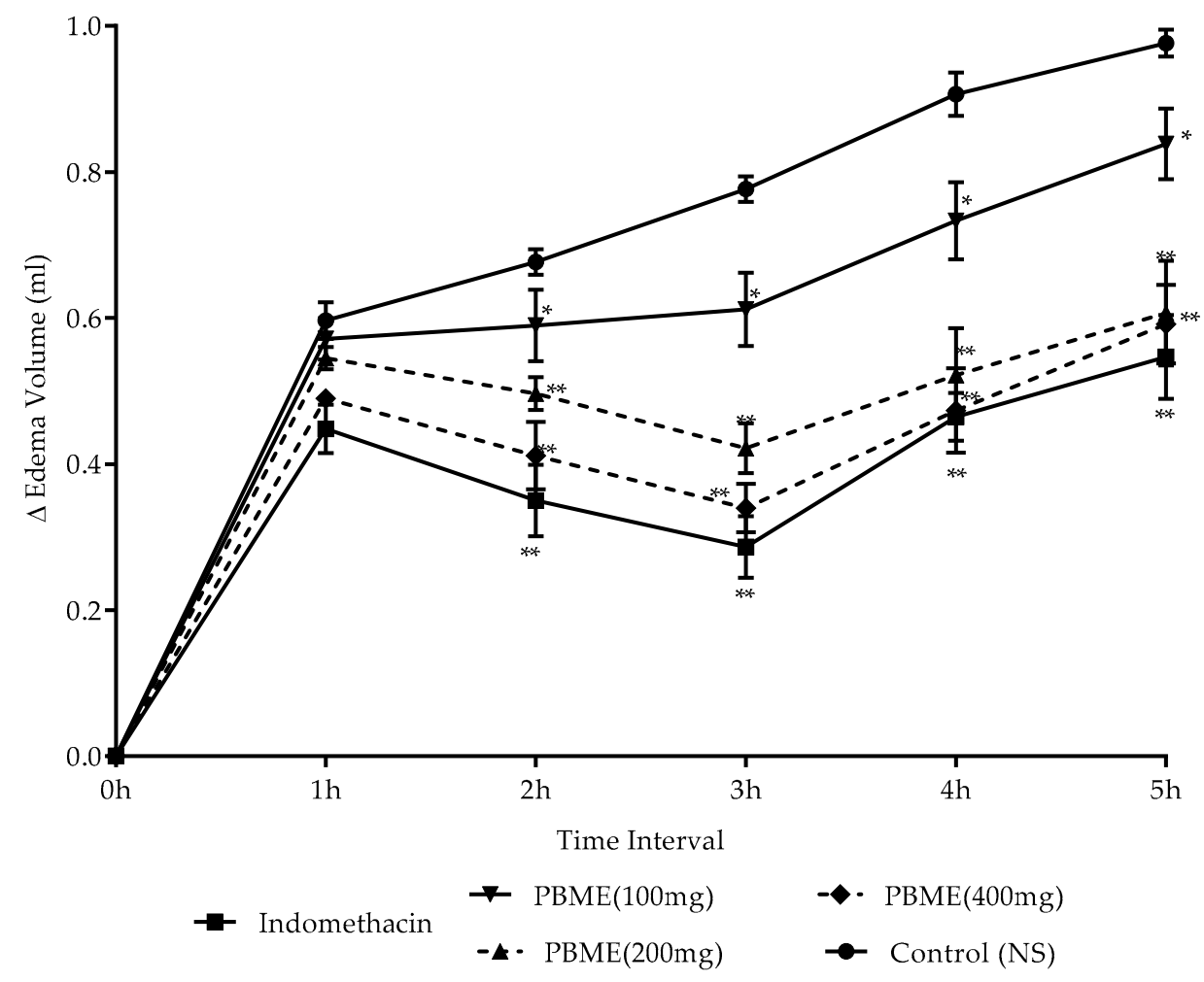

Figure 2. Difference $(\Delta)$ edema volume $(\mathrm{mL})$ on PBME, and indomethacin on rat paw edema induced by carrageenan. Values are mean \pm SD $(n=6)$. $p$-value measured by ANOVA followed with Dunnett's test post hoc multiple comparisons. ${ }^{*} p<0.01$ and ${ }^{* *} p<0.001$ compared to control.

\section{Discussion}

With effective ethnopharmacological value, $P$. bengalensis is widely used by different tribes as an effective herbal medicine. Literature surveys have revealed that leaves of $P$. bengalensis are being used for alleviating headaches, fevers $[15,18]$ and body pains [16]. This study observed the activity of $P$. bengalensis on pain, inflammation and pyrexia, to ascertain scientific rationales behind its ethnical practice. Our study validates the efficacy of methanol extract of $P$. bengalensis against induced pain, inflammation, and pyrexia. These useful biological activities may be attributed to tannins, flavonoids, alkaloids, glycosides, phenols, steroids, saponins, and terpenoids, as reported in previous phytochemical screenings [19].

The PBME has a wide safety margin. The lethal dose of PBME could not be acquired because no fetal reactions were detected at the highest dose, $4000 \mathrm{mg} / \mathrm{kg}$. Three selective doses, 100, 200 and $400 \mathrm{mg} / \mathrm{kg}$, were chosen for the in vivo study.

Fever, a major host defense mechanism is a brain-mediated response to respond on injury or infections with elevated body temperature [26]. This response is triggered by exo-pyrogens and facilitated by endo-pyrogens like TNF- $\alpha$, IL- $1 \beta$, IL-6, corticotrophin release factor (CRF), endothelin-1 (ET-1), preformed pyrogenic factor (PFPF), bradykinin, and prostaglandin $\mathrm{E}_{2}\left(\mathrm{PGE}_{2}\right)$ [27]. The ability of methanol extracted from $P$. bengalensis to reduce body temperature indicates the presence of components that can regulate either the $\mathrm{PGE}_{2}$-dependent fever activated cyclooxygenase (COX) in the preoptic zone of hypothalamus, or PGE 2 -independent fever activated by PFPF, CRF, and ET-1; or both [28]. The established literature reports suggests that alkaloids prohibit prostaglandin $\mathrm{E}_{2}$ [29] and flavonoids suppress TNF- $\alpha$, [30]. Both of those compounds were reported in the leaf extracts of P. bengalensis [19]. Further investigation of those chemical compounds present in the plant leaf would be worthwhile, for determining the specific pathway of antipyretic activity.

Estimation of antinociceptive activity of plant based traditional medicine is a complex phenomenon. A single method is not precise enough to distinguish the origin and efficacy of the antinociceptive 
activity [31]. Therefore, a chemical and thermal nociception model was accessed during the experimental procedures. All the methods were used to distinguish between central or peripheral antinociceptive effect [32].

The acetic acid-induced nociception test is a non-specific pain model mediated by the prostaglandin pathway [33] to sensitize nociceptive neurons [34]. Pain stimulation from these processes are supposed to be responsible for abdominal contraction, forelimbs' expansion and body elongation [35]. In this study, the extract's antagonism of the acetic acid induced a writhing response probably resulted from either the blockage of the prostaglandin pathway or interference with the transduction cascade in efferent nociceptors [36]. Moreover, naloxone did not reverse the activity of PBME, suggesting that the effects do not depend entirely on opioid receptors. Phytochemicals in PBME may inactivate other endogenic pain stimulants responsible for nerve excitation that requires future investigation.

The thermal stimulus on rats is a highly sensitive method to evaluate central antinociceptive activity [37]. Paw licking and the jumping response on a warm surface are the components assessed here. Both are supraspinal reactions deactivated by central acting painkillers but not by peripheral anti-inflammatory drugs. In our study, P. bengalensis extract elevated reaction time, suggesting the presence of centrally active antinociceptive components. Since naloxone did not completely reverse the PBME action, opioid receptors did not completely facilitate the process, alhough it might be modulated by the components that act on ion channels and block the release of excitatory neurotransmitters involved in nociception [38].

The formalin-induced pain model characterized by early phase and late phase is a reliable method for possible mechanism studies [39]. The early neurogenic pain phase is stimulated by formalin to activate substance $\mathrm{P}$ after its injection. The late inflammatory pain phase is mediated through serotonin, histamine, prostaglandins, and bradykinin release [40]. The central antinociceptive agents equally suppress both stages, while peripheral agents inhibit only the later phase [34,41]. In our study, P. bengalensis extract reduced the duration of paw licking all phases, suggesting the presence of components that act like both central and peripheral antinociceptive drugs.

The observed antinociceptive activity of the extract in several test models anticipated the involvement of centrally and peripherally activating chemical constituents. However, the peripheral and central activities of the leaf extract were not reversed by naloxone, which confirmed the non-involvement of the opioid receptors for antinociceptive activity. It is therefore, reasonable to assume that the antinociceptive activity was mediated by inhibition of the COX pathway or modulation of ions channels involved in nociceptive neurons. This could be a highlight in the search for new analgesic components to substitute centrally acting opioids, which have unwanted side effects [42].

The rat paw swelling by carrageenan injection is a widely recognized biphasic model for anti-edematogenic study. The initial event $(0-1 \mathrm{~h})$ is local inflammation triggered by bradykinin, histamine, tachykinins, and reactive species. However, the late event $(1-5 \mathrm{~h})$ is linked with COX action, PGs, and neutrophil infiltration [24]. The P. bengalensis extract alleviated edema volume mostly in late phase (1-5 h), in a pattern similar to indomethacin. There are lines of evidence suggesting the anti-edema property of flavonoids, phenols, and terpenoids [43-45] which were found in PBME. P. bengalensis extract may inhibit the production of PGs or leukocytes in the anti-edematogenic process.

\section{Conclusions}

The assessment of the antipyretic, antinociceptive, and anti-inflammatory activities of methanol extract from $P$. bengalensis leaves shows that extracts have considerable effects. The study supports the traditional claims for fever, headache, and body pain management. The focus for the future is aimed towards isolation of chemical constituents from PBME. Results from the ongoing experiments will be reported in due course.

Author Contributions: S.A., B.A., and P.A. contributed to collecting the plant sample; the identification and confection of herbarium; running the laboratory work; analysis of the data; and drafting of the paper. S.A., B.A., and K.P. contributed to biological studies. S.A., S.K.M., N.K., and R.P.B. contributed to critical reading of the 
manuscript. N.K., B.S., J.S.-R., and R.P.B. designed the study, supervised the laboratory work, and contributed to the critical reading of the manuscript. W.N.S. and N.K. revised and edited the manuscript. N.K. contributed as the lead supervisor for this research work. All the authors have read the final manuscript and approved the submission.

Funding: This research received no external funding.

Acknowledgments: The authors acknowledged the Universal College of Medical Sciences, Bhairahawa, Nepal, and Koirala, Research Institute for Biotechnology and Biodiversity, Kathmandu, Nepal, for supporting this research.

Conflicts of Interest: The authors declare no conflict of interest.

\section{References}

1. Nathan, C. Points of control in inflammation. Nature 2002, 420, 846-852. [CrossRef] [PubMed]

2. Merskey, H.; Bogduk, N. Classification of Chronic Pain, 2nd ed.; IASP Press, International Association for the Study of Pain: Seattle, WA, USA, 1994; pp. 210-214.

3. Tirumalasetty, J.; Ubedulla, S.; Chandrasekhar, N.; Kishan, P.; Rasamal, K. Evaluation of antipyretic activity of alcoholic extract of Vitex nigundo leaves in PGE1 induced pyrexia model in Albino rats. J. Chem. Pharm. Res. 2012, 4, 3015-3019.

4. Punchard, N.A.; Whelan, C.J.; Adcock, I. The Journal of Inflammation. J. Inflamm. 2004, 1, 1. [CrossRef] [PubMed]

5. Labianca, R.; Sarzi-Puttini, P.; Zuccaro, S.M.; Cherubino, P.; Vellucci, R.; Fornasari, D. Adverse effects associated with non-opioid and opioid treatment in patients with chronic pain. Clin. Drug. Investig. 2012, 32, 53-63. [CrossRef]

6. Atanasov, A.G.; Waltenberger, B.; Pferschy-Wenzig, E.-M.; Linder, T.; Wawrosch, C.; Uhrin, P.; Temml, V.; Wang, L.; Schwaiger, S.; Heiss, E.H. Discovery and resupply of pharmacologically active plant-derived natural products: A review. Biotechnol. Adv. 2015, 33, 1582-1614. [CrossRef] [PubMed]

7. Ekor, M. The growing use of herbal medicines: Issues relating to adverse reactions and challenges in monitoring safety. Front. Pharmacol. 2014, 4, 177. [CrossRef]

8. Gurung, S.; Škalko-Basnet, N. Wound healing properties of Carica papaya latex: In vivo evaluation in mice burn model. J. Ethnopharmacol. 2009, 121, 338-341. [CrossRef]

9. Bodeker, G.; Ong, C.-K. WHO Global Atlas of Traditional, Complementary and Alternative Medicine; World Health Organization: Kobe, Japan, 2005; Volume 1.

10. Braun, L.A.; Tiralongo, E.; Wilkinson, J.M.; Spitzer, O.; Bailey, M.; Poole, S.; Dooley, M. Perceptions, use and attitudes of pharmacy customers on complementary medicines and pharmacy practice. BMC Complement. Altern. Med. 2010, 10, 38. [CrossRef]

11. Liem, A. "I've Only Just Heard About It": Complementary and Alternative Medicine Knowledge and Educational Needs of Clinical Psychologists in Indonesia. Medicina 2019, 55, 333. [CrossRef]

12. Aryal, S.; Baniya, M.; Danakhu, K.; Kuwar, P.; Gurung, R.; Koirala, N. Total Phenolic, Flavonoid Content and Antioxidant Potential of Wild Vegetables from Western Nepal. Plants 2019, 8, 96. [CrossRef]

13. Uprety, Y.; Poudel, R.C.; Gurung, J.; Chettri, N.; Chaudhary, R.P. Traditional use and management of NTFPs in Kangchenjunga Landscape: Implications for conservation and livelihoods. J. Ethnobiol. Ethnomed. 2016, 12, 19. [CrossRef] [PubMed]

14. Dangol, D.R. Economic uses of forest plant resources in western Chitwan, Nepal. Banko Janakari 2002, 12, 56-64. [PubMed]

15. Manandhar, N.P. Useful Wild Plants of Nepal; Franz Steiner Verlag Wiesbaden GMBH: Kathmandu, Nepal, 1989.

16. Das, S.; Dash, S.K.; Padhy, S.N. Ethno-medicinal Informations from Orissa State, India, A Review. J. Hum. Ecol. 2003, 14, 165-227. [CrossRef]

17. Ashwini, S.; Khade, A.; Basawaraj, H.; Shrishail, G. A comprehensive review on Pogostemon benghalensis (Burm. f.) O. Kuntze. Res. Rev. J. Pharmacogn. Phytochem. 2013, 1, 10-15.

18. Ghimire, K.; Bastakoti, R.R. Ethnomedicinal knowledge and healthcare practices among the Tharus of Nawalparasi district in central Nepal. For. Ecol. Manag. 2009, 257, 2066-2072. [CrossRef] 
19. Patel, M.; Antala, B.; Dowerah, E.; Senthilkumar, R.; Lahkar, M. Antitumor activity of Pogostemon benghalensis Linn. on ehrlich ascites carcinoma tumor bearing mice. J. Cancer. Res. Ther. 2014, 10, 1071-1075. [CrossRef] [PubMed]

20. Thoppil, J.; Tajo, A.; Minija, J.; Deena, M.; Sreeranjini, K.; Leeja, L.; Sivadasan, M.; Alfarhan, A. Antimicrobial activity of the essential oils of three species of Pogostemon. J. Environ. Biol. 2014, 35, 795. [PubMed]

21. Taylor, R.S.L.; Manandhar, N.P.; Hudson, J.B.; Towers, G.H.N. Antiviral activities of Nepalese medicinal plants. J. Ethnopharmacol. 1996, 52, 157-163. [CrossRef]

22. Pahari, S.K.; Singh, S.P.; Banmali, M.P.; Thaler, F.J.L.; Rathour, M.S.S. Ethical Guidelines for the Care and Use of Animals in Health Research in Nepal; Nepal Health Research Council: Kathmandu, Nepal, 2005.

23. OECD. Test No. 425: Acute Oral Toxicity: Up-and-Down Procedure; OECD: Paris, France, 2008.

24. Pingsusaen, P.; Kunanusorn, P.; Khonsung, P.; Chiranthanut, N.; Panthong, A.; Rujjanawate, C. Investigation of anti-inflammatory, antinociceptive and antipyretic activities of Stahlianthus involucratus rhizome ethanol extract. J. Ethnopharmacol. 2015, 162, 199-206. [CrossRef]

25. Sulaiman, M.R.; Zakaria, Z.A.; Bujarimin, A.S.; Somchit, M.N.; Israf, D.A.; Moin, S. Evaluation of Moringa oleifera Aqueous Extract for Antinociceptive and Anti-Inflammatory Activities in Animal Models. Pharm. Biol. 2008, 46, 838-845. [CrossRef]

26. Roth, J.; Blatteis, C.M. Mechanisms of fever production and lysis: Lessons from experimental LPS fever. Compr. Physiol. 2011, 4, 1563-1604.

27. Malvar, D.d.C.; Soares, D.M.; Fabrício, A.S.C.; Kanashiro, A.; Machado, R.R.; Figueiredo, M.J.; Rae, G.A.; de Souza, G.E.P. The antipyretic effect of dipyrone is unrelated to inhibition of PGE(2) synthesis in the hypothalamus. Br. J. Pharmacol. 2011, 162, 1401-1409. [CrossRef] [PubMed]

28. Do Malvar, D.C.; Aguiar, F.A.; de Vaz, A.L.L.; Assis, D.C.; de Melo, M.C.; Jabor, V.A.; Kalapothakis, E.; Ferreira, S.H.; Clososki, G.C.; de Souza, G.E. Dipyrone metabolite 4-MAA induces hypothermia and inhibits PGE2-dependent and -independent fever while 4-AA only blocks PGE2-dependent fever. Br. J. Pharmacol. 2014, 171, 3666-3679. [CrossRef] [PubMed]

29. Backhouse, N.; Delporte, C.; Givernau, M.; Cassels, B.; Valenzuela, A.; Speisky, H. Anti-inflammatory and antipyretic effects of boldine. Agents Actions 1994, 42, 114-117. [CrossRef] [PubMed]

30. Chang, C.-P.; Huang, W.-T.; Cheng, B.-C.; Hsu, C.-C.; Lin, M.-T. The flavonoid baicalin protects against cerebrovascular dysfunction and brain inflammation in experimental heatstroke. Neuropharmacology 2007, 52, 1024-1033. [CrossRef]

31. Dickenson, A. Mechanisms of central hypersensitivity: Excitatory amino acid mechanisms and their control. In The Pharmacology of Pain; Springer: Geneva, Switzerland, 1997; pp. 167-210.

32. Umukoro, S.; Ashorobi, R.B. Further studies on the antinociceptive action of aqueous seed extract of Aframomum melegueta. J. Ethnopharmacol. 2007, 109, 501-504. [CrossRef]

33. Deraedt, R.; Jouquey, S.; Delevallée, F.; Flahaut, M. Release of prostaglandins E and F in an algogenic reaction and its inhibition. Eur. J Pharmacol. 1980, 61, 17-24. [CrossRef]

34. Adzu, B.; Amos, S.; Kapu, S.D.; Gamaniel, K.S. Anti-inflammatory and anti-nociceptive effects of Sphaeranthus senegalensis. J. Ethnopharmacol. 2003, 84, 169-173. [CrossRef]

35. Oh, Y.-C.; Jeong, Y.H.; Cho, W.-K.; Ha, J.-H.; Gu, M.J.; Ma, J.Y. Anti-Inflammatory and Analgesic Effects of Pyeongwisan on LPS-Stimulated Murine Macrophages and Mouse Models of Acetic Acid-Induced Writhing Response and Xylene-Induced Ear Edema. Int. J. Mol. Sci. 2015, 16, 1232-1251. [CrossRef]

36. Jia, Q.; Su, W.; Peng, W.; Li, P.; Wang, Y. Anti-diarrhoea and analgesic activities of the methanol extract and its fractions of Jasminum amplexicaule Buch.-Ham.(Oleaceae). J. Ethnopharmacol. 2008, 119, 299-304. [CrossRef]

37. Pini, L.A.; Vitale, G.; Ottani, A.; Sandrini, M. Naloxone-reversible antinociception by paracetamol in the rat. J. Pharmacol. Exp. Ther. 1997, 280, 934-940. [PubMed]

38. Patel, R.; Montagut-Bordas, C.; Dickenson, A.H. Calcium channel modulation as a target in chronic pain control. Br. J. Pharmacol. 2018, 175, 2173-2184. [CrossRef] [PubMed]

39. Sarmento-Neto, J.F.; Do Nascimento, L.G.; Felipe, C.F.B.; De Sousa, D.P. Analgesic Potential of Essential Oils. Molecules 2016, 21, 20. [CrossRef]

40. Maione, F.; Minosi, P.; Di Giannuario, A.; Raucci, F.; Chini, M.G.; De Vita, S.; Bifulco, G.; Mascolo, N.; Pieretti, S. Long-Lasting Anti-Inflammatory and Antinociceptive Effects of Acute Ammonium Glycyrrhizinate Administration: Pharmacological, Biochemical, and Docking Studies. Molecules 2019, 24, 2453. [CrossRef] [PubMed] 
41. Li, X.; Sahbaie, P.; Zheng, M.; Ritchie, J.; Peltz, G.; Mogil, J.S.; Clark, J.D. Expression genetics identifies spinal mechanisms supporting formalin late phase behaviors. Mol. Pain 2010, 6, 11. [CrossRef] [PubMed]

42. Gutstein, H.B. Opioid analgesics. In Goodman E Gilman's the Pharmacological Basis of Therapeutics, 11th ed.; Laurence, L., Brunton, J.S., Lazo, K., Parker, L., Eds.; The McGraw-Hill Companies, Inc.: New York, NY, USA, 2005; pp. 569-619.

43. Khan, I.; Nisar, M.; Ebad, F.; Nadeem, S.; Saeed, M.; Khan, H.; Samiullah; Khuda, F.; Karim, N.; Ahmad, Z. Anti-inflammatory activities of Sieboldogenin from Smilax china Linn.: Experimental and computational studies. J. Ethnopharmacol. 2009, 121, 175-177. [CrossRef] [PubMed]

44. Koirala, N.; Thuan, N.H.; Ghimire, G.P.; Thang, D.V.; Sohng, J.K. Methylation of flavonoids: Chemical structures, bioactivities, progress and perspectives for biotechnological production. Enzyme Microb. Technol. 2016, 86, 103-116. [CrossRef] [PubMed]

45. Koirala, N.; Pandey, R.P.; Parajuli, P.; Jung, H.J.; Sohng, J.K. Methylation and subsequent glycosylation of 7,8-dihydroxyflavone. J. Biotechnol. 2014, 184, 128-137. [CrossRef] [PubMed]

(C) 2019 by the authors. Licensee MDPI, Basel, Switzerland. This article is an open access article distributed under the terms and conditions of the Creative Commons Attribution (CC BY) license (http://creativecommons.org/licenses/by/4.0/). 